\title{
Thanasis Georgakopoulos
}

Freie Universität, Berlin-Excellence Cluster Topoi

\author{
Athina Sioupi \\ Aristotle University of Thessaloniki
}

\section{Framing the difference between Sources and Goals in Change of Possession events: A corpus-based study in German and Modern Greek $^{*}$}

\begin{abstract}
This paper investigates the hypothesis of the preference of Goals over Sources in the representation of Change of Possession events. Applying a corpusbased methodology, we analyse two verbs belonging to this event type, namely BUY and SELL, in German and Modern Greek, two languages that differ with respect to the patterns they use to encode motion events (i.e. a Satellite- and a Verb-framed language respectively). We find that both languages conform to the general tendency reported across languages to give prominence to the Goal: SELL is more likely to occur with the optional Goal Prepositional Phrase than BUY is with the optional Source Prepositional Phrase. Additionally, we address the question as to whether languages showing different patterns regarding the encoding of the Path differ with respect to the predominance of the Goal over the Source in events that express non-prototypical dislocation. Our findings indicate that the typological difference of the two languages has an indirect effect on the representation of Path elements for these particular verbs: German expresses the optional Prepositional
\end{abstract}

\footnotetext{
* This research was supported by the Aristotle University of Thessaloniki Research Committee Postdoctoral Grant, which was awarded to the first author in the year 2012. Previous versions of the paper were presented by both authors at the 6th International Conference on Corpus Linguistics (May 2014; Universidad de Las Palmas de Gran Canaria) and by the first author at the 6th International Conference of the German Cognitive Linguistics Association (September-October 2014; Universität Erlangen). We are indebted to the audience of the conferences for the constructive discussions. Thanks are also due to Dionysis Goutsos (University of Athens, Greece) for giving us access to the raw data from the Corpus of Greek Texts, Tatiana Nikitina (UMR 8135 CNRSINaLCO), and to Anna Piata (University of Geneva, Switzerland) for their valuable comments on the manuscript. Very special thanks are due to Demetra Katis (University of Athens, Greece) for stimulating comments. Finally, we thank the editors and an anonymous reviewer who contributed greatly to clarifying our main points, as well as Anna McNay for checking our English. The usual disclaimers apply, of course.
} 
Phrase (the TO- and the FROM-Phrase) more often than Greek, most probably because of the Goal optional element in German (the To-Phrase). Therefore, we conclude that the degree of robustness of the Goal bias is higher in German than it is in Greek.

Keywords: Source-Goal asymmetry, Change of Possession events, frames, Satelliteand Verb-framed languages

\section{Introduction}

Recent literature has demonstrated that Goals and Sources behave asymmetrically at both the linguistic and non-linguistic level (e.g. Ikegami 1987; Ihara and Fuijita 2000; Stefanowitsch and Rohde 2004; Lakusta and Landau 2005; Papafragou 2010; Lakusta and Landau 2012; Lakusta and Carey 2014). In most studies, the wheel shows a clear preference and spins towards the Goal. In this respect, Goals are often considered as the unmarked member of the contrasting pair Source-Goal (Ikegami 1987; Fillmore 1997). The prevalence of Goal over Source of motion is also evident in the way the relevant markers develop semantically: Goal markers exhibit more robust patterns of semantic extension compared to Source ones (Kabata 2013). Additionally, corpus studies confirm the preference for including Goals in motion events (see Stefanowitsch and Rohde 2004), although these studies report that Goal bias is more a tendency than a categorical rule. This preference for the Goal has been attributed to a cognitive bias favouring the endpoint over the starting point of motion (see Regier and Zheng 2007; cf. Lakusta and Carey 2014). ${ }^{1}$

Despite the fact that the Source-Goal asymmetry is well documented on the basis of both impressionistic and empirical data, there are some issues that remain to be addressed. For example, does the Goal bias in encoding motion events apply

\footnotetext{
${ }^{1}$ Some researchers challenge the degree of pervasiveness of the prevalence of Goals over Sources. Although the conceptual bias is taken for granted in the literature, it has been argued that it is not reflected in semantic or syntactic asymmetries between Goals and Sources (Gehrke 2008, but see Filip 2003; Nam 2004; Landau and Zukowski 2003). Also, there is evidence from studies suggesting that the linguistic encoding of the two Path types balances between symmetry and asymmetry (Kopecka 2012). In some cases, the asymmetry seems to work in the opposite direction, i.e. in favour of the Source-oriented expressions, hence a Source bias (Petersen 2012). It is an open empirical question whether and under which conditions a particular language shows a preference for Goals rather than Sources; this issue calls for separate treatment and is beyond the scope of the present paper.
} 
also to events that express non-prototypical dislocation (cf. Lakusta and Landau 2005)? And do languages that show different patterns as to the encoding of the path differ with respect to the predominance of the Goal over the Source in nonprototypical spatial events?

In this paper, we address these questions by investigating whether German and Modern Greek (henceforth Greek), languages that show different patterns in encoding Path (see below), prefer Goals over Sources in the representation of nonprototypical spatial events, such as Change of Possession events. Our starting point is a finding by Lakusta and Landau (2005), who explored the encoding of Goalpaths and Source-paths by English speaking children. Lakusta and Landau asked among other things - whether the information related to the Goal is more often omitted than the information related to the Source across a wide range of domains, such as Manner of Motion, Change of State, Attachment/Detachment and Change of Possession events. They found that children included Goals in their descriptions of the various events more often than Sources, thereby attesting to a Goal bias not only in spatial expressions but also in non-spatial ones.

Our choice to focus on German and Greek is justified by the fact that the two languages are examples of languages which are claimed to prefer a Satellite- and a Verb-framed pattern respectively. In German, Path information appears in modifiers outside the verb, while manner of motion is usually encoded within the verb (cf. Figure 1; see Tschander 1999; Talmy 2000a, Talmy 2000b; Berthele 2006). This is illustrated in example (1):

$\begin{array}{llll}\text { (1) Der } & \text { Linguist } & \text { rennt durch } & \text { die Korridore. } \\ \text { the } & \text { linguist } & \text { runs through } & \text { the corridor.ACC }\end{array}$

'The linguist runs through the corridor'.

(Berthele 2006: 9)

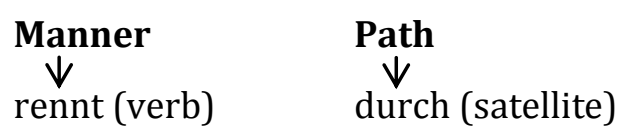

Figure 1. German (satellite-framed language)

On the other hand, in Greek Path is encoded within the verb whereas Manner appears elsewhere (see Figure 2; see Antonopoulou 1987; Bassea-Bezentakou 
1992; Talmy 2000b: 66-67; Papafragou et al. 2002; 2006; Selimis 2007; Johanson and Papafragou 2010; Papafragou and Selimis 2010, Selimis and Katis 2010, among others). This is exemplified in (2):

\begin{tabular}{|c|c|c|c|}
\hline (2) 0 & ylosoloyos bike & sto $^{2} \quad \gamma$ rafio & (trehodas). \\
\hline the & linguist.NOM entered.3SG.PFV & to-the office.ACC ${ }^{3}$ & (running) \\
\hline
\end{tabular}
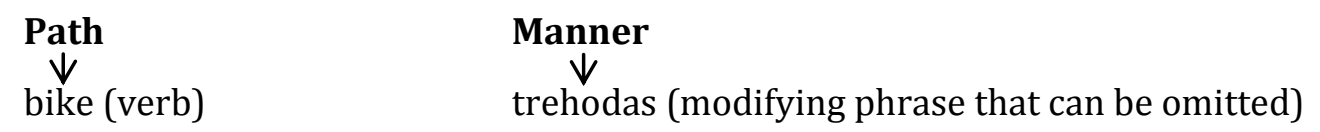

Figure 2. Greek (Verb-framed language)

A recent study by Johanson and Papafragou (2010) has shown that the tendency seemingly characterising most languages in making Goal information more prominent may be more or less strong depending upon the Talmian typology of motion: the speakers of a Satellite-framed language (English) employ a larger number of adposition types than the speakers of a Verb-framed language (Greek). The possible effect of the Talmian typological dichotomy is also visible in other ways. For instance, it has been reported that the speakers of English express locative information in more detail than the speakers of Verb-framed Spanish (see Slobin 1996; see also Ibarretxe-Antuñano 2009; Selimis and Katis 2010). More precisely, Slobin (1996: 199-201) found that in elicited narratives, Spanish speakers described downward motion with bare verbs more often than English speakers. In other words, in instances where the PP was optional, a Verb-framed language omitted the PP more frequently than a Satellite-framed language.

Although these findings are related to motion events which can be taken as prototypical, i.e. intransitive motion events, we anticipate that similar differences will be reproduced in non-prototypical motion events, more particularly in transitive ones which code such additional information as change of possession (see Jackendoff 1983; Lakusta and Landau 2005). Importantly, Change of

\footnotetext{
${ }^{2}$ Preposition $s e+t o . D E F=$ sto. The preposition se ('to') occurs in both Goal and Locative relations in Greek, but the Goal reading is only available with motion verbs (cf. Horrocks and Stavrou 2007 for extensive discussion and references).

${ }^{3}$ Abbreviations used in interlinear glosses:

$\mathrm{ACC}=$ accusative, $\mathrm{DAT}=$ dative, $\mathrm{DEF}=$ definite, $\mathrm{INDEF}=$ indefinite, $\mathrm{NOM}=$ nominative, $2 .=$ second person, $3 .=$ third person, $\mathrm{PAST}=$ past tense, $\mathrm{PFV}=$ perfective aspect, $\mathrm{SG}=$ singular, $\mathrm{SUBJ}=$ subjunctive .
} 
Possession events have a similar semantic structure to change of location events. For example, Bill sold his book to Anna has a similar semantic structure to Mary fell to the ground. The crucial relation for our purposes is the relation between the Figure ( $\mathrm{F}=$ his book in the former; $\mathrm{F}=$ Mary in the latter) and the Ground ( $\mathrm{G}=$ Anna in the former; $\mathrm{G}=$ the ground in the latter). In both cases, the figure's basic location shifts from one point (Bill in the former; Mary's initial location in the latter) to another in space (Anna in the former; the ground in the latter). The book changes possession and is being transferred to Anna in the same way that Mary changes her location in space and falls to the ground (cf. Lakusta and Landau 2005: 4; Talmy 2000b: 35). Note also that in both examples the PP can be dropped (Bill sold his book and Mary fell are grammatical sentences). Interestingly, change of possession (seen as a parallel to change of location) is an inherent property of the verb, not a property that only emerges in the presence of the Goal PP. In other words, change of possession takes place even when the Buyer is not explicitly expressed in the sentence. This differs, for example, from what happens in such process verbs as run, where a necessary condition for the change in location to be signaled is the presence of a Goal PP, such as into the store. Buy/ sell verbs resemble verbs of dislocation more than process verbs which could either involve dislocation or occur in the same location. Taking into consideration the above similarities of the two event types and the different properties of the two languages, we expect that, in Change of Possession events, Greek will omit the optional PP more often than German.

Our study has been undertaken within the Frame-Semantic model, which focuses on the way lexical units activate frame knowledge. 'Frame' represents a system of concepts that is organised, structured and related in such a way that, to understand a particular concept, you need to understand the whole knowledge structure to which it belongs (Fillmore 1982 [2006]: 373; 1985: 224). Our analysis is based on Fillmore's textbook example, the COMMERCIAL EVENT frame. We focus on the translational equivalents of the English verbs buy/sell in German and Greek, namely kaufen/verkaufen and agorazo/pulao respectively. These verbs belong to the COMMERCIAL EVENT frame, which describes an action involving a Giver and a Receiver, exchanging Money and Goods. This frame provides the framework of knowledge required in order to make sense of these two single words. More 
specifically, knowing the meaning of BUY and SELL requires knowing the semantic structure of the COMMERCIAL EVENT frame with which they are both associated (for the COMMERCIAL EVENT frame, see Fillmore 1982 [2006]: 378; 1985; Boas 2001: 66). BuY and SELL in German and Greek are similar in that their argument structure contains the same number of arguments and the Prepositional Phrase element, be it a Source P or a Goal P respectively, is optional in both verbs. This point is crucial to the purposes of this study. Under the hypothesis that Goal assumes a more important role than Source, we expect that Goal PPs will occur more frequently than Source PPs. We anticipate, for instance, that Goal PPs such as to Anna in Bill sold his book to Anna will be explicitly expressed more often than Source PPs such as from Bill in Anna bought a car from Bill. In the latter cases, the Source element will usually be dropped (for more discussion see Section 3).

In the following sections, we present the methodology used to extract and process the data (Section 2); we report and discuss the results of the corpus study concerning the two verbs in the languages under investigation (Section 3); and offer some concluding remarks, while also identifying directions for future research (Section 4).

\section{Data and Method}

The Greek data come from the Corpus of Greek Texts (CST; http://sek.edu.gr/; last accessed: August 2013), which includes ca. 30 million words (see Goutsos 2010 for a detailed description). The size of the Greek corpus used in this study is ca. $14,500,000$ words. The German data were extracted from the COSMAS II corpus compiled by IDS Mannheim (http://www.ids-mannheim.de/cosmas2/; accessed August 2013; see Kupietz et al. 2010). For the present purposes, a corpus of written German was chosen (Hamburger Morgenpost, diverse Schriftsteller, spektrumdirekt, ca. 21 million words). To ensure the comparability of these two independent monolingual corpora, we selected the same subcorpora viz. newspapers, literature and academic texts/texts covering the latest news on science (both labelled as 'academic texts'). 
We first retrieved all instances of the verbs BUY and SELL in German and Greek, i.e. kaufen/agorazo and verkaufen ${ }^{4} /$ poulao respectively, which are often characterised as belonging to the category of Change of Possession events. The overall tokens retrieved ranged from 900 to 2,000 extractions. After the retrieval of the material, we performed a random sorting with MS Excel 2010 by means of the random number generator formula "=rand()". Then we checked each token manually and removed the invalid hits. An important caveat is that cases of the verbs BUY and SELL co-occurring with a bare singular count noun as a complement (agorazo proti katikia 'I buy first property', i.e. 'I buy a first property') ${ }^{5}$ or with a bare plural (agorazi/ computer/metoxes 'he/ she buys computers/shares', er kaufte Bücher 'he bought books', er verkaufte Versicherungen 'he sold insurances') were excluded in both languages, since they denote a permanent meaning property in imperfective aspect. ${ }^{6}$ Also, intransitive meanings of SELL (pulise ekatomiria antitipa 'it sold millions of exemplars') and of BUY, which is syntactically realised as passive voice in Greek (agorastike apo ton patera tis 'it was bought by her father'), are superfluous and have therefore not been included in the analysis. In both corpora, metaphors and idioms were considered invalid observations. Regarding the German corpus, we discarded cases of the verbs with the reflexive pronoun sich ('herself/himself/itself' (er kaufte sich einen Döner 'he bought himself a doner') as well as middle constructions, i.e. transitive sentences in the active with an accusative reflexive pronoun in the position of the direct object that appear in $3^{\text {rd }}$ person singular or plural (bis heute verkaufte sich das Buch in 40 Sprachen 'the book has sold in 40 languages until now'). ${ }^{7}$ Additionally, we left out such particle verbs as einkaufen ('do the shopping'; Die MOPO kaufte im Supermarkt ein 'the

\footnotetext{
${ }^{4}$ The verb BUY in German is a particle verb; the prefix ver- is a contraction of three different prepositions that in Gothic appear separately as faur (vor = 'before', vorbei = 'over'), fra (weg = 'away') and fair (heraus = 'out', hindurch = 'through'). In the present-day language, there is an extreme semantic variety of different meaning of the ver-verbs, i.e. eggresive meaning (verändern = 'to change'), igressive (verbauen = 'to plug'), and causative (verfilmen = 'to film'), among others (see Fleischer and Barz 2012).

${ }^{5}$ See Sioupi (2001), Sioupi (2002) for extensive discussion and references on bare singular count nouns.

${ }^{6}$ The point is made quite clearly in Moser (1994); see also Sioupi (2014).

${ }^{7}$ For more discussion on the middle construction in German see also Abraham (1995), Sioupi (1998) and Steinbach (2000), among others.
} 
MOPO did the shopping in the supermarket'), abkaufen ('to buy something from someone'; [...] kaufte ihr das Kind ab '[...] bought the kid from her'). ${ }^{8}$

We continued the manual checking until both samples consisted of $n=200$ valid tokens of the target phenomenon. This means that the data used in the analysis comprise a total of 400 extracted tokens per verb, i.e. 200 extractions for each language. The total number of valid observations amount to 800 (i.e. 2 verbs $\times$ 2 languages $\times 200$ tokens). These observations were coded for certain properties, which can be seen in Table 1. The right-hand column presents the labeling of the properties and the middle column shows the number of levels.

Table 1. Properties used to tag the data

\begin{tabular}{lll}
\hline Property & Levels & Labeling \\
\hline LANGUAGE & 2 & German; Greek \\
TEXT TYPE & 3 & Newspapers; Literature; Academic texts \\
OPTIONAL ELEMENT & 2 & Yes; No \\
TYPE OF VERB & 2 & Buy; Sell \\
\hline
\end{tabular}

In order to compare the distribution of Source-Goal elements in the two languages, we used Pearson's chi-square test. To test whether the typological difference of the two languages has an impact on the robustness of the Goal bias, we subjected the data to a log-linear analysis, which examines the relationship between the three categorical variables, viz. LANGUAGE, OPTIONAL ELEMENT, TYPE OF VERB. In all cases, the alpha level was set at .05 .

In the next section, we present and discuss the data.

\section{Change of Possession events: Analysis of the data}

The COMMERCIAL EVENT frame: As already mentioned (Section 1), this study focuses on two verbs belonging to the COMMERCIAL EVENT frame, namely BUY and SELL, both of which require the same number of arguments, yet differ in terms of the profiled participants. As illustrated in the figures below, BUY profiles the role of the Buyer and her actions with respect to the Goods (with the Money and the Seller being

\footnotetext{
${ }^{8}$ All examples used in this section come from our sample.
} 
gapped) and SELL focuses on the relation between the Seller and the Goods (leaving in the background the Money and the Buyer).

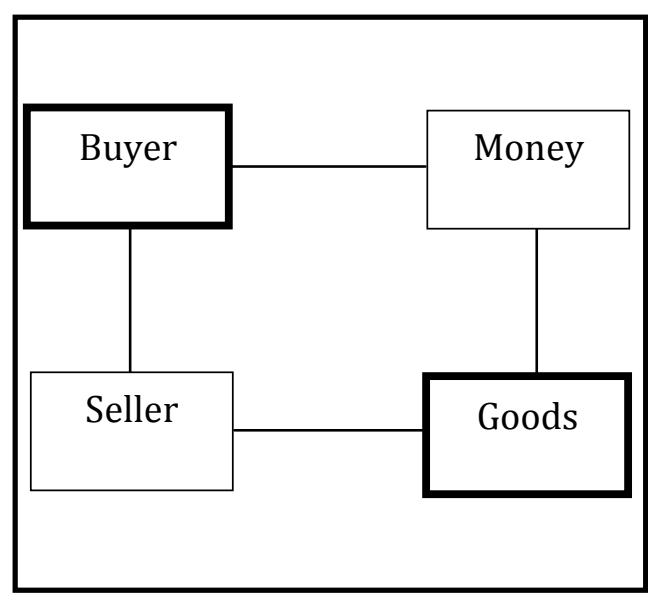

Figure 3. The profiled attributes (in bold) of BUY in the COMMERCIAL EVENT frame

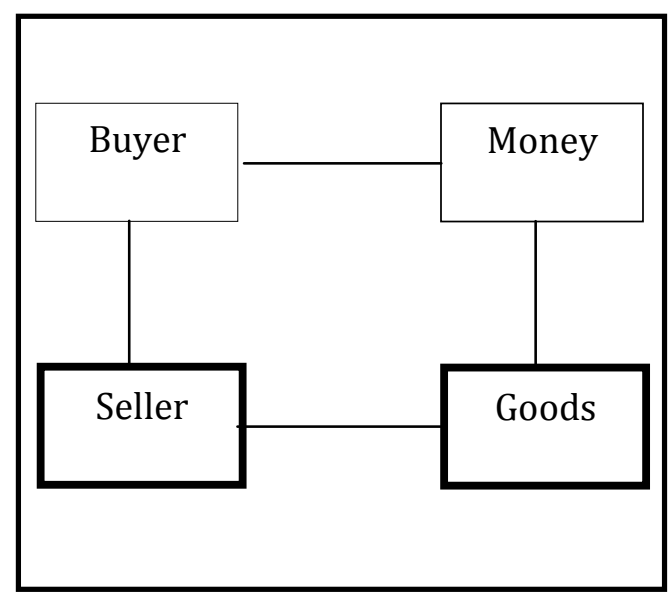

Figure 4. The profiled attributes (in bold) of SELL in the COMMERCIAL EVENT frame

Consider the following examples from German and Greek:

(3)

\begin{tabular}{|c|c|c|c|c|}
\hline $\begin{array}{l}\text { Aus } \\
\text { from }\end{array}$ & $\begin{array}{l}\text { Verzweiflung } \\
\text { desperation }\end{array}$ & $\begin{array}{l}\text { verkaufte } \\
\text { sold.3SG.PAST }\end{array}$ & $\begin{array}{l}\text { schon } \\
\text { already }\end{array}$ & $\begin{array}{l}\text { jede } \\
\text { each }\end{array}$ \\
\hline Frau & ihr & Baby. & & \\
\hline voman & her & baby & & \\
\hline
\end{tabular}

'Every second woman sold her baby out of desperation'.

[HMP12]

(4) $\begin{array}{llllll}0 & \text { proeðros } & \theta \mathrm{a} & \text { pulisi } & \text { tin omaða to } \\ \text { the } & \text { President } & \text { PART } & \end{array}$ $\Delta$ ekemvrio.

December. ACC

'The President will sell the team in December'.

[WOPG18-0378]

\begin{tabular}{|c|c|c|c|c|}
\hline Schon & mit & 19 & Jahren kaufte & sie \\
\hline already & with & 19 & years bought.3SG.PAST & she \\
\hline
\end{tabular}


first work of art

'When she turned 19 (years old), she bought her first work of art'.

[HMP08]

(6) As pume, $\gamma$ a paradigma, oti o pelatis

SUBJ say, for example, that the customer.Nom

Өeli na ayorasi ena cd musikis.

wants SUBJ buy a cd music.2SG

'Let's say, for example, that the customer wants to buy a CD'.

[WRPG16-9284]

What all the above examples have in common is that they foreground the Goods; they differ in that (3) and (4) profile the Seller, while (5) and (6) profile the Buyer. Also, all instances show that BUY and SELL express the same number of arguments, namely one entity realised as the subject, be it a Seller or a Buyer, and one entity, the Goods, which is realised as the object. However, it is possible for elements other than the highlighted ones to appear in the sentence. For instance, in the act of selling one can add a third participant, e.g. a Buyer, who would be the entity to which the Seller gives the Goods (see ex. 7 and 8).

$\begin{array}{lllll}\text { Die Firma } & \text { verkaufte } & \text { in den } & \text { Folgejahren } \\ \text { the company } & \text { sold.3sG.PAST } & \text { in the following years } \\ \text { Rechner an } & \text { Universitäten. } & & \\ \text { computers to } & \text { universities } & & \end{array}$

'In the following years, the Company sold computers to the Universities'. $[\mathrm{SPK}]$

(8) Os to etos 1974 pulisa ke ta 6

until the year 1974 sold.3SG.PFV and the 6

ðiamerismata $\quad$ se 6 ðiaforetikus ayorastes.

apartments to 6 different buyers

'By 1974, I had sold all 6 apartments to 6 different buyers'.

[WRPG17-1791] 
Similarly, in the act of buying, apart from the Buyer and the Goods, the Seller could also be explicitly mentioned in order to indicate from whom the transaction is initiated, as shown in examples 9 and 10 below:

$\begin{array}{lllll}\text { Er } & \text { kaufte } & \text { Beruhigungspillen } & \text { von } & \text { einem } \\ \text { he } & \text { bought.3SG.PAST } & \text { sedative pills } & \text { from } & \text { INEF.DAT }\end{array}$

Junkie.

junkie

'He bought sedative pills from a junkie'.

[HMP11]

(10)

$\begin{array}{llllll}\text { Sintoma } & \text { apektise } & \text { ke } & \text { ðeftero } & \text { plio } & \text { pu to } \\ \text { soon } & \text { acquired.3SG.PFV } & \text { and } & \text { second } & \text { ship that the } \\ \text { ayorase } & \text { apo } & \text { tin } & \text { eteria } & & \text { Evyeviði. }\end{array}$

bought.3SG.PFV from the company.ACC Eugenides'

'He soon had a second ship which he bought from the Eugenides

company'.

[WRPG17-2380]

The optional elements in (7)-(10) are introduced by the Goal prepositions an and se and by the Source prepositions von and apo, in German and Greek, respectively.

From the above, it becomes evident that the two verbs are equivalent in two respects. Firstly, they involve the same number of obligatory attributes and, secondly, they are both likely to bring to the fore (that is, to explicitly express) an optional element. The expression or omission of the optional element is the crucial issue for the purposes of this study. Following Lakusta and Landau (2005), we argue that the choice to explicitly express the optional element will be determined by the bias toward the expression of the Goal. Thus, under the GOAL-over-SOURCEpredominance hypothesis, it is assumed that Goal-paths (when co-occurring with Goal-profiled verbs, like SELL) will be more frequently expressed than Source-paths (when co-occurring with Source-profiled verbs, like BUY). 
Results: Table 2 summarises the results of the 800 sentences for the two languages (2 verbs $\times 2$ languages $\times 200$ tokens).

Table 2. Change of Possession verbs in German and Greek

\begin{tabular}{|c|c|c|c|c|}
\hline \multirow[t]{2}{*}{ verb } & \multicolumn{2}{|c|}{$\begin{array}{c}\text { German } \\
\text { Optional Element }\end{array}$} & \multicolumn{2}{|c|}{$\begin{array}{c}\text { Greek } \\
\text { Optional Element }\end{array}$} \\
\hline & Yes & No & Yes & No \\
\hline$B U Y$ & 14 & 186 & 25 & 175 \\
\hline SELL & 100 & 100 & 70 & 130 \\
\hline
\end{tabular}

The important finding here is that the expression of the optional element with SELL in Greek is significantly more frequent than with BUY, $\chi^{2}(1)=27.96, p<.001$. Figure 5 shows the results obtained for the Greek verbs agorazo and pulao.

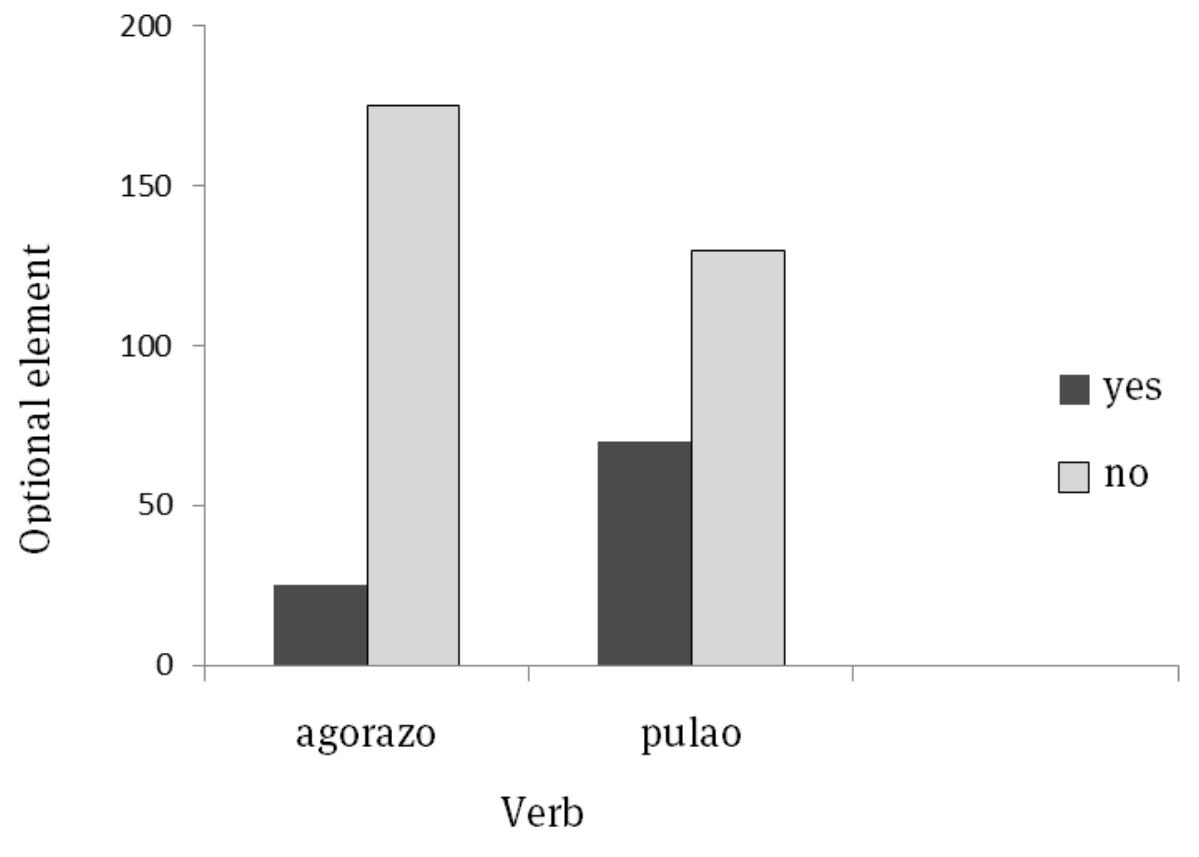

Figure 5. The expression and omission of the optional element in agorazo and pulao

The chi-square test for the German data also revealed a significant difference, $\chi^{2}(1)$ $=90.74, p<.001$. The optional element with SELL in German is significantly more frequent than with BUY. Figure 6 shows the results obtained for the German verbs kaufen and verkaufen. 


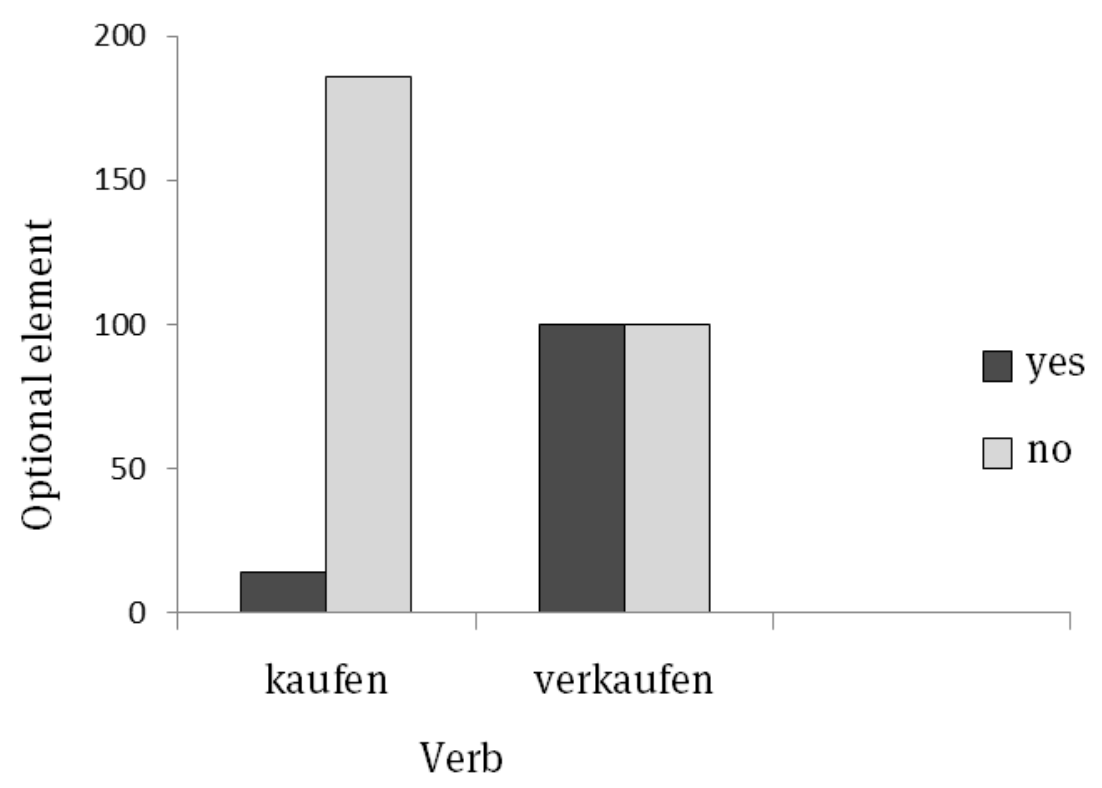

Figure 6. The expression and omission of the optional element in kaufen and verkaufen

The above results confirm the preferential treatment of Goal elements as compared to Source elements in the two languages. Therefore, two typologically different languages show similar behaviour as to which path element assumes a more salient role. The imbalance between the two Path types is retained across all text types of our sample, as shown in Figure 7, therefore no genre considerations should be made as to the Source-Goal asymmetry.

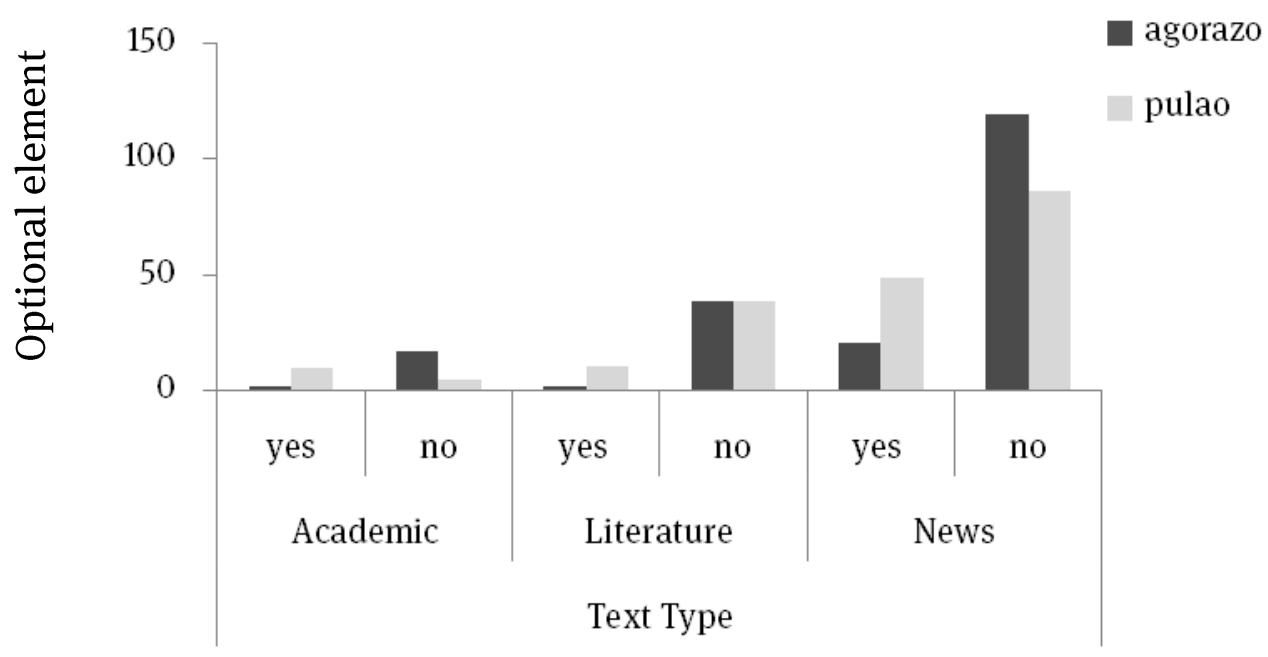

Figure 7a. $N$ of the presence vs. absence of the optional element of BUY and SELL across the subcorpora in Greek. 


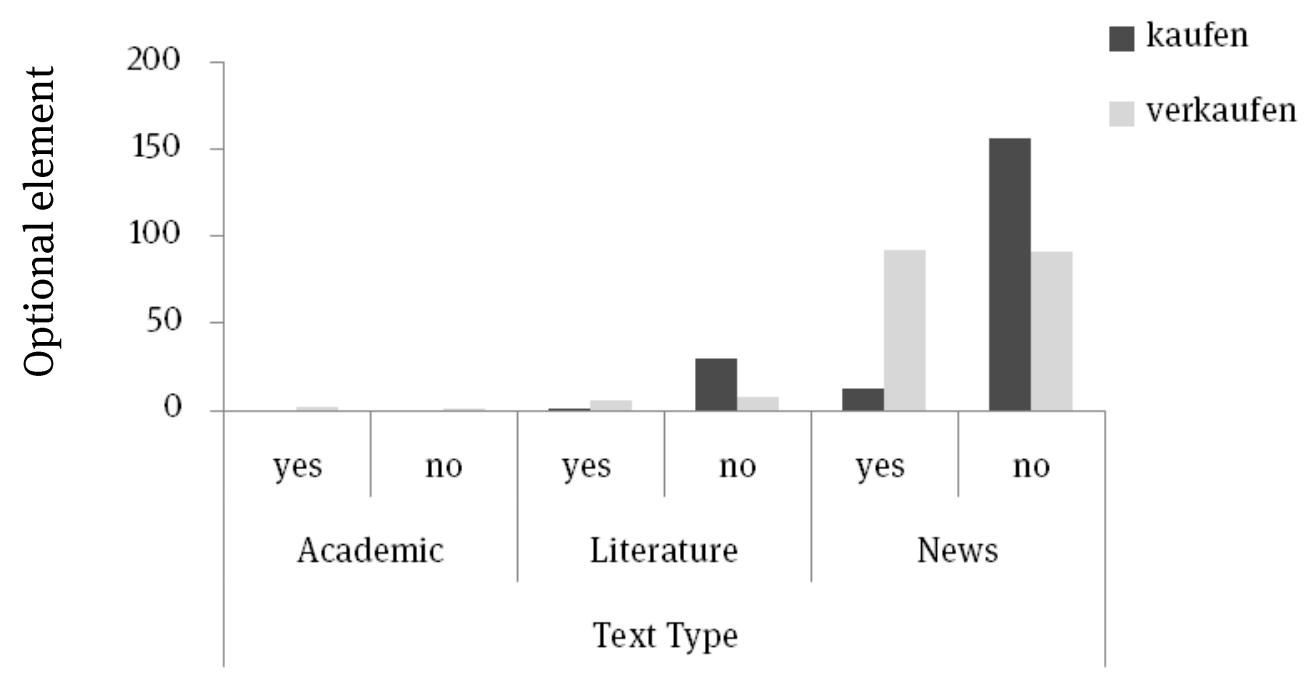

Figure $7 \mathrm{~b} . N$ of the presence vs. absence of the optional element of BUY and SELL across the subcorpora in German.

It should be underlined that academic texts, as expected, do not provide enough data for a more thorough analysis; although a limited sample, academic texts still add the variety of text types considered in this study. In addition, we included this text type in the analysis because our study is embedded within a wider project, which investigates the Goal bias hypothesis across many verb-types, e.g. Manner of Motion, Path of Motion, Change of State verbs, and across various text types. We opted, therefore, to report the results obtained from all the dimensions examined in the wider project.

The question that arises now is whether the typological difference between German and Greek affects some aspects of the bias toward the expression of the Goal. In Section 1 we pointed out that, given the different properties of the two languages, we expect that PPs in German will be more frequent than PPs in Greek. To examine this hypothesis, we need to investigate the relationship between the variables Language (German vs. Greek), Type of verb (BUY vs. SELL), and Optional element (explicit coding vs. implicit through omission). In order to test the relationship between the three categorical variables, we performed a log-linear analysis. The three-way log-linear analysis produced a final model that retained all effects. The likelihood ratio of this model was $\chi^{2}(0)=0, p=1$. This indicated that the highest-order interaction (Language $\times$ Type of verb $\times$ Expression of the optional element) was significant, $\chi^{2}(1)=10.01, p<.05$. To break down this effect, 
first we refer again to the result obtained by performing separate chi-square tests on the Type of verb and the expression vs. omission of the Optional element for Greek and German. For Greek, there was a significant association between the type of the verb and whether or not the optional element is expressed, $\chi^{2}(1)=27.96, p$ $<.001$; this is the case in German as well, $\chi^{2}(1)=90.74, p<.001$. Odds ratios indicated that the odds of explicit expression of the optional element were 12.5 times lower if the verb BUY was used instead of SELL in German, while in Greek it was 3.86 times lower. Additionally, we conducted an analysis to identify which verb drives the difference in the expression of the optional element. In doing so, we performed a chi-square test on the Type of verb and (only on) the explicitly expressed Optional element in German and Greek. The results indicate that there is an association between the two, $\chi^{2}(1)=6.72, p<.001$. Conforming to our hypothesis that a Verb-framed language will omit the (optional) PP more frequently than a Satellite-framed language, we found that in German the optional element is coded more often $(n=114)$ than Greek $(n=95)$. Since the Source element in Greek is more frequent than the corresponding element in German (GR: $n=25$ vs. GER: $n=14$ ), we may conclude that the critical factor for the observed difference is the Goal optional element in German. Therefore, the analysis seems to reveal one important similarity and one fundamental difference between German and Greek. For one, in both languages the optional element is more likely to be expressed with the SELL verb, thus corroborating the cross-linguistic Goal bias. However, the two languages differ in their degree of preference for Goal, with a stronger preference in German than Greek.

\section{Conclusions}

In this paper, we have examined the hypothesis that Goal prevails over Source in the representation of Change of Possession events, i.e. in non-prototypical spatial events. We reported the results of two corpus studies in German and in Greek, two languages that show different patterns with respect to the encoding of motion events, the former being categorised as a Satellite- and the latter as a Verb-framed language. 
Specifically, our corpus investigation included the contrastive analysis of the verbs BUY and SELL and showed that there is an imbalance in the Source-Goal frequency distribution. In both languages, the vector pointed clearly to the direction of the Goal. In both German and Greek, the optional element, which is realised as a PP, is more likely to occur with SELL than with BUY. This finding is in line with the results presented by Lakusta and Landau (2005), who found that English speaking children omit Sources more often than Goals across a wide range of event types, including Change of Possession events. One key difference between German and Greek is that, in the former, the PP is explicitly expressed more often than in the latter. The analysis of the data indicates that the important factor explaining this difference is the greater number of German Goal PPs. Therefore, Goal bias is more pervasive in German than in Greek. If we attempt to situate our findings within the context of the broader question regarding the interplay between Universality and Language Specificity (see Johanson and Papafragou 2010), it is clear that the preference for Goals in both languages favours the Universality claim (i.e. the general Goal bias reported across languages), while their difference regarding the degree of robustness of the Goal bias supports the Language Specificity claim, which predicts that the demands of linguistic encoding imposed by each language may influence the linguistic representation at various levels.

We hope that these findings encourage further cross-linguistic corpus-based research, which will add more variables - e.g. more verb types, such as verbs coding Paths inherently ('ascend') - in order to arrive at a safer conclusion about the degree of similarity and difference between German and Greek regarding the Source-Goal asymmetry. An expanded data set could determine whether the preferential treatment of Goals holds across various events and, in addition, whether the various event types in German retain a more robust bias compared to Greek, or if the differences may be related to language-specific aspects of the verbs' semantics in German, i.e. particle verbs, derivations by the prefix ver- ${ }^{9}$. Needless to say, future research should also consider widening its dataset and investigating other non-prototypical spatial events involving Sources and Goals. More extensive exploitation of corpora is necessary for validating or perhaps rejecting results from

\footnotetext{
${ }^{9}$ We thank an anonymous reviewer for pointing that out to us.
} 
other sources, such as experimental findings. It can thus more generally contribute towards possible convergences of empirical evidence, which are a priority in Cognitive Linguistics.

\section{References}

Abraham, Werner. 1995. Deutsche Syntax im Sprachenvergleich. Grundlegung einer typologischen Syntax des Deutschen. Gunter Narr: Tübingen.

Antonopoulou, Eleni. 1987. Prototype Theory and the Meaning of Verbs, with Special Reference to Modern Greek Verbs of Motion. SOAS; University of London dissertation.

Bassea-Bezantakou, Christine. 1992. Simasiologikes Theories tor Rimaton Kiniseos tis Neas Ellinikis Glossas. [A Semantic Analysis of Motion Verbs in Modern Greek]. Kardamitsa: Athens.

Berthele, Raphael. 2006. Ort und Weg. Die sprachliche Raumreferenz in Varietäten des Deutschen, Rätoromanischen und Französischen. Berlin: Walter de Gruyter.

Boas, Hans C. 2001. Frame Semantics as a framework for describing polysemy and syntactic structures of English and German motion verbs in contrastive computational lexicography. In Paul Rayson, Andrew Wilson, Tony McEnery, Andrew Hardie \& Shereen Khoja (eds.), Proceedings of Corpus Linguistics 2001, 6473. U.K: Lancaster.

Filip, Hana. 2003. Prefixes and the delimitation of events. Journal of Slavic Linguistics, 11(1). 55-101.

Fillmore, Charles J. 2006 [1982]. Frame Semantics. In Geeraerts, Dirk (ed.).Cognitive Linguistics: Basic readings. 373-400. Berlin/ New York: Mouton de Gruyter.

Fillmore, Charles. J. 1997. Lectures on deixis. Stanford, CA: CSLI Publications.

Fleischer, Wolfgang \& Irmird Barz. 2012. Wortbildung der Deutschen Gegenwartssprache. 4th edn. Berlin: de Gruyter.

Gehrke, Berit. 2008. Ps in Motion. On the semantics and syntax of P elements and motion events. Utrecht: University of Utrecht dissertation.

Goutsos, Dionysis. 2010. The Corpus of Greek Texts: a reference corpus for Modern Greek. Corpora 5(1). 29-44.

Jackendoff, Ray. 1983. Semantics and cognition. Cambridge, MA: MIT Press.

Johanson, Megan \& Anna Papafragou. 2010. Universality and Language Specificity in the acquisition of path vocabulary. Proceedings from the 34th Annual Boston University on Language Development. 185-196. Somerville, MA: Cascadilla Press.

Ibarretxe-Antuñano, Iraide. 2009. Path Salience in Motion Events. In: Jiansheng Guo, Elena Lieven, Nancy Budwig, Susan Erwin-Tripp, Keiko Nakamura \& Şeyda Özçalişkan (eds.), Cross-Linguistic Approaches to the Psychology of Language: Research in the Tradition of Dan Isaac Slobin. 403-414. New York: Psychology Press.

Ihara, Hiroko \& Ikuyo Fujita. 2000. A cognitive approach to errors in case marking in Japanese agrammatism: The priority of the goal -ni over the source -kara. In Foolen, Ad \& Frederike van der Leek (ed.), Constructions in Cognitive Linguistics: Selected papers from the Fifth International Cognitive Linguistics Conference, Amsterdam 1997. 123-140. Amsterdam/ Philadelphia: John Benjamins.

Ikegami, Yoshihiko. 1987. 'Source' vs. 'goal': A case of linguistic dissymmetry. In: Dirven, René \& Günter Radden (eds.), Concepts of Case, 122-146. Tübingen: Narr.

Kabata, Kaori. 2013. Goal-source asymmetry and crosslinguistic grammaticalization patterns: a cognitive-typological approach. Language Sciences 36. 78-89. 
Kopecka, Annetta. 2012. Semantic granularity of placement and removal in Polish. In Kopecka, Anetta \& Bhuvana Narasimhan (eds.). Events of Putting and Taking. A Crosslinguistic Perspective. 327-347. Amsterdam/Philadelphia: John Benjamins Publishing Company.

Kupietz, Marc, Cyril Belica, Holger Keibel \& Andreas Witt. 2010. The German Reference Corpus DeReKo: A primordial sample for linguistic research. In Nicoletta Calzolari (ed.), Proceedings of the 7th conference on International Language Resources and Evaluation (LREC 2010). Valletta, Malta: ELRA, 1848-1854.

Lakusta, Laura M. \& Barbara Landau. 2005. Starting at the end: The importance of goals in spatial language. Cognition 96. 1-33.

Lakusta, Laura M. \& Barbara Landau. 2012. Language and Memory for Motion Events: Origins of the Asymmetry Between Source and Goal Paths. Cognitive Science 36(3). 517-44.

Lakusta, Laura M. \& Susan Carey. 2014. Twelve-Month-Old Infants' Encoding of Goal and Source Paths in Agentive and Non-Agentive Motion Events. Language Learning and Development 12/2014. 11(2). 1-24. DOI: 10.1080/15475441.2014.896168.

Landau, Barbara \& Andrea Zukowski. 2003. Objects, motions and paths: Spatial language in children with Williams syndrome. Developmental Neuropsychology. 23. 107-139.

Moser, Amalia. 1994. Pion ke Apopsis tu Rimatos. [Aktionsart and Aspects of Verb]. Parousia Monograph Series 30. Athens: Parousia.

Nam, Seungho. 2004. Goal and source: asymmetry in their syntax and semantics. Paper presented at the Workshop on Event Structure, University of Leipzig, 17-19 March.

Papafragou, Anna. 2010. Source-Goal asymmetries in motion representation: Implications for language production and comprehension. Cognitive Science 34. 1064-1092.

Papafragou, Anna, Christine Massey, \& Lila Gleitman. 2002. Shake, rattle, 'n' roll: The representation of motion in language and cognition. Cognition 84. 189-219.

Papafragou, Anna, Christine Massey, \& Lila Gleitman. 2006. When English Proposes What Greek Presupposes. The Cross-Linguistic Encoding of Motion Events. Cognition 98(3): B75-B87.

Papafragou, Anna, \& Stathis Selimis. 2010. Event categorization and language: A crosslinguistic study of motion. Language and Cognitive Processes 25(2). 224-260.

Petersen, Jan Heegård. 2012. How to put and take in Kalasha. In Kopecka, Anetta \& Bhuvana Narasimhan (eds.), Events of Putting and Taking. A Crosslinguistic Perspective. 349-366. Amsterdam/Philadelphia: John Benjamins Publishing Company.

Regier, Terry \& Mingyu Zheng. 2007. Attention to endpoints: A cross-linguistic constraint on spatial meaning. Cognitive Science 31(4). 705-719.

Selimis, Stathis. 2007. Glosiki kodikopiisi tu eniologikou pediu tis kinisis: kirioleksia ke metafora sta elinika pedion ke enilikon. [Linguistic coding of the concept of motion: Literal and metaphorical expressions in adult and child Greek]. University of Athens dissertation.

Selimis, Stathis \& Demetra Katis. 2010. Motion Descriptions in English and Greek: A CrossTypological Developmental Study of Conversations and Narratives. Linguistik online 42(2/10). 57-76.

Sioupi, Athina. 1998. Domes Mesis Diathesis: Mia sigritiki meleti Ellinikis-Germanikis. [Middle constructions: a comparative study in Greek and German]. University of Athens dissertation.

Sioupi, Athina. 2002. On the syntax and semantics of verb-complement constructions that involve "creation". A comparative study in Greek and German. In Werner Abraham \& Jan-Wouter Zwart (eds.), Issues in formal German(ic) Typology. Linguistik Aktuell 45, 263-284. Amsterdam/Philadelphia: John Benjamins.

Sioupi, Athina. 2014. Aspektdistinktionen im Vergleich. Deutsch/Englisch - Griechisch. Tübingen: Narr. 
Slobin, I. Dan. 1996. Two Ways to Travel: Verbs of Motion in English and Spanish. In Masayoshi Shibatani, \& Sandra A. Thompson (eds.), Grammatical Constructions: Their Form and Meaning, 195-217. Oxford: Oxford University Press.

Stefanowitsch, Anatol \& Ada Rohde. 2004. The goal bias in the encoding of motion events. In Günter Radden \& Klaus-Uwe Panther (eds.), Studies in linguistic motivation, 249268. Berlin \& New York: Mouton de Gruyter.

Steinbach, Markus. 2000. Middle voice: a comparative study in the syntax-semantic interface of German. Amsterdam/Philadelphia: John Benjamins.

Talmy, Leonard. 2000a. Toward a Cognitive Semantics, vol. I: Concept Structuring Systems. Cambridge, MA: MIT Press.

Talmy, Leonard. 2000b. Toward a Cognitive Semantics, vol. II: Typology and process in Concept Structuring. Cambridge, MA: MIT Press.

Tschander, Ladina. 1999. Bewegung und Bewegungsverben. In Ipke Wachsmuth \& Bernhard Jung (eds.), Proceedings der 4. Fachtagung der Gesellschaft für Kognitionswissenschaft. 25-30. Bielefeld: Sankt Augustin. 25-30. 